\title{
INHERITANCE OF FERTILITY RESTORATION INVOLVING ID TYPE CYTOPLASMIC MALE STERILITY SYSTEM IN RICE (Oryza sativa L.) USING TEN DIFFERENT RESTORER LINES
}

\author{
M.J. Hasan ${ }^{*}$, U. Kulsum, N. E. Elahi, A.K.M. Shamsuddin ${ }^{1}$ \\ and M.M. Rahman ${ }^{2}$ \\ Bangladesh Rice Research Institute (BRRI), Gazipur-1701, Bangladesh
}

\begin{abstract}
Inheritance of fertility restoration was studied in crosses involving ten elite restorer lines of rice viz. BR827R, BR168R, BR6723-1-1-2R, M.H.63R, M.H.77R, Gui99R, IR40750R, IR64R, AjayaR and IR44675R and one male sterile line II32A with ID (Indonesian paddy type) sources of cytoplasmic male sterility. The segregation pattern for pollen fertility of $\mathrm{F}_{2}$ and $\mathrm{BC}_{1}$ populations of crosses involving II32A indicated the presence of two independent dominant fertility restoring genes. The mode of action of the two genes varied in different crosses revealing three types of interaction, i.e. epistasis with dominant gene action, epistasis with recessive gene action, and epistasis with incomplete dominance.
\end{abstract}

Keywords: Cytoplasmic male sterility, Fertility restoration, Inheritance,

Oryza sativa

\section{INTRODUCTION}

Precise understanding of genetics of fertility restoration is useful in planning a sound breeding strategy for development of superior restorers in a hybrid breeding program. It may also help in the efficient transfer of restorer genes into other agronomical desirable genotypes. In rice several sources of cytoplasmic genetic male sterility (CMS) have been reported (Virmani and Edwards, 1983). However, extensive research work on identification of restorers and maintainers and on inheritance of fertility restoration has been done on the WA (Wild Abortive) type cytoplasmic source only. Cytoplasmic male sterility (CMS), which causes the production of non-functional pollen and inherited maternally, is important in commercial hybrid seed production (Chen L and Liu YG, 2014)) and breeding program. A number of studies on the relationship between CMS and fertility-restorer

\footnotetext{
*Corresponding author email: jamilbrri@yahoo.com

${ }^{1}$ Professor, Department of Genetics and Plant Breeding, BAU, Mymensingh- 2202

${ }^{2}$ Principal Training Officer, BARC, Dhaka- 1215
} 
genes ( $R f$ ) have been conducted in various plants and may enable a better understanding of genetic differentiation and the interaction between cytoplasmic and nuclear genomes in plants (Budar and Pelletier, 2001). The wild- abortive (WA) type of CMS in rice has been used extensively in commercial production, and its fertility is sporophytically restored by the dominant restorer genes (Suresh et al., 2012; Jing et al., 2001). Fertility-restorer genes are important in the production of hybrid rice. Although a variable number of restorer genes have been proposed in various restorer lines, one or two dominant restorer alleles $(R f 3$ and $R f 4)$ are usually suggested to be responsible for the fertility (Sattari et al., 2008). A major dominant gene with sporophytic action has been reported to be involved in fertility restoration of the WA source. However, most studies involving restorers of WA cytoplasm suggest the presence of two pairs of independent, dominant fertility restorer genes with one gene pair being stronger in action than the other (Cai et al., 2014; Li and Yuan, 1986; Raj and Virmani, 1988; Muker 1990). The maintenance and transference of CMS within natural population of wild rice cannot be separated from $R f$ and it is easy to assume that the restorer genes exist in wild rice. However, the information about the origin, evolutionary relationships and distribution of the fertility-restorer genes for ID CMS system is relatively new and fragmentary. To be able to recognize the $R f$ in wild rice would facilitate not only the exploitation of new $R f$ alleles but also give a better understanding of the origin and evolution of the fertility-restorer genes. With this view, the present study was undertaken to determine the genetic control of fertility restoration of ID-CMS system.

\section{MATERIALS AND METHODS}

The experiment was conducted at the experimental field of Bangladesh Rice Research Institute (BRRI), Gazipur. Three consecutive seasons Boro 2007-08, T. Aman 2008 and Boro 2008-09 were deployed for this experiment. The soil type of the experimental field belongs to the Shallow Red Brown Terrace type under Salna Series of Madhupur Tract (Brammer, 1971; Saheed, 1984) of Agro ecological Zone (AEZ) 28 which is characterized by silty clay with $\mathrm{pH}$ value of 6.5 . The climate of the experimental site is subtropical in nature characterized by heavy rainfall during the months from June to September and scanty in winter with gradual fall of temperature from the month of September. The material consisted of one male sterile line II32A belonging to ID (Indonesian paddy) type source of cytoplasmic male sterility and ten prospective restorer lines. The restorer lines were BR827R, BR168R, BR6723-1-1-2R, M.H.63R, M.H.77R, Gui99R, IR40750R, IR64R, AjayaR and IR44675R. First season $F_{1}$ was raised. The resulting $F_{1}$ 's were selfed as well as backcrossed with their respective female parents to generate $\mathrm{F}_{2}$ and $\mathrm{BC}_{1}$ populations in the second season and final season evaluation was made with pollen fertility of each plant in the $\mathrm{F}_{2}$ and $\mathrm{BC}_{1}$ populations. From each plant, five anthers from different spikelets were collected and their pollen grains were stained in $1 \%$ Iodine Potassium Iodide (IKI) solution. Plants were classified into different fertility-sterility group as 
was done by Chaudhary et al. (1981). Plants with more than $60 \%$ fertility pollen were grouped as fully fertile (FF), those with $30-60 \%$ fertile partial fertile (PF), those having $1-30 \%$ fertile pollen as partial sterile (PS) and those which had $0 \%$ were grouped as completely sterile (CS) under an optical microscope. One panicle from each plant of $F_{1}$ population was bagged before flowering for spikelet fertility analysis and spikelet fertility of bagged panicle was count at maturity stage. At maturity, the bagged panicle was examined for seed set and classified as fertile $(81-100 \%$ seed set), partially fertile $(31-80 \%)$, partially sterile $(1-30 \%)$ and sterile $(<1 \%)$. The parental lines, $\mathrm{F} 1$ progenies, $250 \mathrm{~F}_{2}$ plants for each segregating population were grown and evaluated in the same conditions for phenotypic and pollen fertility rate was used as the main criteria for the evaluation of fertile and sterile plants. $\mathrm{F}_{1}$ 's contained two rows, $\mathrm{F}_{2}$ seven rows, $\mathrm{BC}_{1}$ five rows with 37 plants/row and non replicated. Chi-square analysis was used to estimate the distribution pattern of $R f$ alleles with ID type source of CMS lines. Measurement of pollen fertility was made on all plants in each of the entries. Twenty to thirty spikelets were collected from each primary panicle and fixed in $70 \%$ alcohol. From these spikelets 10-12 anthers were collected at random and smear in IKI (1\%) and examined under optical microscope. Plants were classified into different fertility-sterility group as was done by Chaudhary et al., (1981). Plants with more than $60 \%$ fertility pollen were grouped as fully fertile (FF), those with $30-60 \%$ fertile partial fertile (PF), those having $1-30 \%$ fertile pollen as partial sterile (PS) and those which had 0\% were grouped as completely sterile (CS) under an optical microscope. The pollen fertility were computed and expressed in percentage for each $\mathrm{F}_{1} \mathrm{~s}, \mathrm{~F}_{2}$ and $\mathrm{BC}_{1}$ population as follows:-

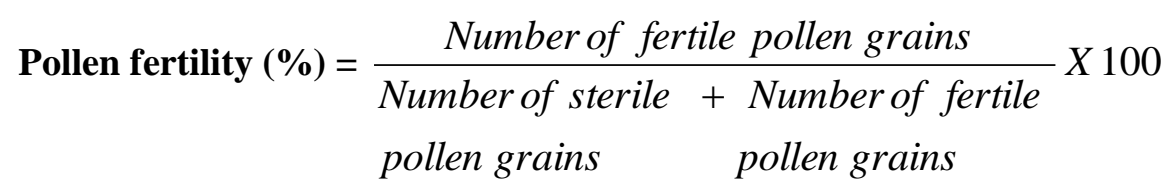

At maturity, the bagged panicle of F1 population was examined for seed set and classified as fertile (71-100\% seed set), partially fertile (31-70\%), partially sterile $(1-30 \%)$ and sterile $(<1 \%)$. Plate 1 is given the pictorial view of completely sterile (CS), full fertile (FF), partially fertile (PF) and partially sterile (PS) pollen.

\section{RESULTS AND DISCUSSION}

Pollen fertility, spikelet fertility and standard error of mean of $\mathrm{F}_{1}$ 's along with their parents were shown in Table 1 . Pollen fertility of $F_{1}$ ranged from 70-80\% and the highest was obtained from II32A/BR168R while the lowest from II32A/M.H.77R. On the other hand, spikelet fertility of the same cross combinations ranged from $74-82 \%$ and suggested that pollen fertility little bit differ with spikelet fertility at the time of maturity. It might be due to pollen abortion at different cell 
division stage. Pollen fertility and spikelet fertility of the parents ranged from 72-95 $\%$ and $72-88 \%$ respectively (Table 1 ).

According to pollen and spikelet fertility classification category all entries fallen into fertile class. Segregation patterns for pollen fertility in $F_{2}$ population of II32A with ten restorer lines are stated in table 2 . The pollen fertility results indicated that relatively few genes were involved in fertility restoration in the crosses studied. In the present study, the inheritance of fertility restoration in the cross II32A/BR827R revealed an F2 segregation ratio of 12:3:1 (FF: SF: CS), indicating the involvement of two dominant genes which exhibited dominant epistasis (Table 2). This suggested that two dominant genes seem to control the fertility restoration. This is an agreement with the findinngs of Sreedhar et al. (2011). The effect of one of the two dominant genes in restoring fertility appeared to be strong and as good as the two together while the other gene showed weak restoration.

The F2 populations of the cross II32A/BR6723-1-1-2R, II32A/M.H.63R, II32A/M.H.77R, II32A/IR40750R and II32A/IR64R exhibited a similar trend of segregation ratio of 12:3:1 of FF: SF: CS type of plants, also indicating the epistasis with dominant type gene action controlled by two dominant genes. When the CMS line II32A was crossed with the restorer line Gui99R, the F2 segregation for pollen fertility fall into the digenic ratio 9:3:4 (FF: SF: CS) (Table 2). The results indicated the involvement of the digenic supplementary or an epistasis with recessive gene action. Assuming that two dominant fertility restoring genes involved in this action but one of the two genes appeared more effective than the other. The F2 ratio of 9:3:4 involving supplementary or epistasis with recessive gene action has been reported earlier by Huang et al. (2012). Again when the CMS lines crossed with the restorer line BR168R, the F2 segregation for pollen fertility showed semi-epistatic ratio 9:6:1 (FF: SF: CS). This variation in the behavior of fertility restoring genes could be due to either to the presence of different restoring genes in the ten restorers studied or to differential penetrance and expressivity of these restorer genes depending on the nuclear genotype of the female parent. Continuous variation with regard to pollen fertility is generally attributed to modifier genes and environmental influences. Similar trend were observed in F2 population with restorer line AjayaR and IR44675R (Table 2). For further confirmation of the segregation patterns, pollen fertility of $\mathrm{BC} 1$ generations were also studied and presented in Table 3. The pollen fertility analysis in crosses involving II32A with BR827R, BR6723-1-1-2R, M.H.63R, M.H.77R, IR40750R and IR64R indicated segregation ratios of 12:3:1 and 2:1:1 of full fertile, semi fertile and complete sterile plants in $\mathrm{F} 2$ and $\mathrm{BC} 1$ generation, respectively (Table $2 \&$ Table 3 ).

This suggests that the restorer lines carried two independent dominant fertility restoring genes and one of the two genes had a duplicate effect that exposed higher expression than the other gene and it alone could restore fertility (dominant epistasis). Similar findings have been reported by Jakkrit et al. (2014) and Muker (1990). On 
the other hand, the crosses of II32A with BR168R, Ajaya R and IR44675R displayed epistasis with incomplete dominance as their $\mathrm{F} 2$ and $\mathrm{BC} 1$ populations segregated in 9:6:1 and 1:2:1 ratios, respectively, for full fertile, semi fertile and complete sterile plants. The cross II32A with Gui99R showed segregation ratio in F 2 and BC1 populations as 9:3:4 and 1:1:2 indicated the pattern of recessive epistasis. Sohu and Phul (1995) reported similar results which are in agreement with the present findings but cyto sources of the CMS line was Gambiaca. From this, it is clearly evident that ID type sources of CMS line II32A followed similar pattern of fertility restoration system like WA and Gambiaca sources of CMS lines.

\section{CONCLUSION}

Spikelet fertility analysis might be that a plant with partial pollen fertility may give complete spikelet fertility because sufficient pollen would be available to effect fertilization. Similarly, a partially sterile plant on the basis of pollen fertility may be completely sterile on the basis of spikelet fertility if its anthers fail to dehisce. Based on the results obtained, it was concluded that the inheritance of male sterility and fertility restoration was conditioned by a pair of alleles, dominant and recessive, at a single locus interacting with the male sterile cytoplasm, and that the mode of action of the two genes varied in different crosses revealing three types of interaction, i.e., epistasis with dominant gene action, epistasis with recessive gene action, and epistasis with incomplete dominance.

\section{REFERENCES}

Budar F. and Pelletier G.2001. Male sterility in plants: occurrence, determinism, significance and use. Life Science, 324: 543-550

Brammer, H. 1971. Soil resources, Soil Survey Project, Bangladesh. AGL. SF/Pak. 6. Technical report 3. 22

Cai, J., Dai, Z.J., Zhu, H.T., Zeng, R.Z., Zhang, Z.M., Ma, T.F. and Zhang G.Q. 2014. Comparative analysis of fertility restoration genes for WA, Y, and DA cytoplasmic male sterility in rice. Biol Plant. doi:10.1007/s10535-013-0385-2

Chaudhary, R.C., Virmani S.S. and Khush G.S. 1981. Patterns of pollen abortion in some Cytoplasmic genetic male sterile lines of rice. Oryza, 18: 140-152

Chen, L. and Liu Y.G. 2014. Male sterility and fertility restoration in crops. Annu Rev Plant Biol, 65:579-606

Huang, W.C., Hu, J., Yu, C.C., Huang, Q., Wan, L., Wang, L.L., Qin, X.J., Ji, Y.X., Zhu, R.S., Li, S.Q. and Zhu, Y.G. 2012. Two non-allelic nuclear genes restore fertility in a gametophytic pattern and enhance abiotic stress tolerance in the hybrid rice plant. Theor Appl Genet 124:799-807

Jakkrit, S., Prapa, S. and Tanee S. 2014. Heterosis and inheritance of fertility-restorer genes in rice Science Asia 40: 48-52 
Jing, R.C., Li, X.M., Yi P. and Zhu Y.G. 2001. Mapping fertility-restoring genes of rice WA cytoplasmic male sterility using SSLP markers. Botanical Bulletin of Academia Sinica, 42: 167-171. Li, Y.C. and Yuan L.P. 1986. Genetic analysis of fertility restoration in male sterile lines of rice. In: Rice Genetics. Proc. Int. Rice Genet. Symp. 27-31 May, 1985. IRRI, 200Manila, Philippines, pp. 617-632

Muker, H.S. 1990. Studies of male sterility fertility restoration and seed set in hybrid rice. Ph. D. Diss., Punjab Agric. Univ., Ludhiana, India

Raj, K.G. and Virmani S.S. 1988. Genetics of fertility restoration of "WA" type cytoplasmic malesterility in rice. Crop Science, 28: 787-792

Sattari, M., Kathiresan, A., Gregorio, G.B. and Virmani S.S. 2008. Comparative genetic analysis and molecular mapping of fertility restoration genes for WA, Dissi, and Gambiaca cytoplasmic male sterility systems in rice. Euphytica, 160:305-315

Saheed, S. M. 1984. Soils of Bangladesh: General Soil types. Soil Resources Development Institute (SRDI), Dhaka, Bangladesh. p3.

Sohu V.S. and. Phul P.S. 1995. Inheritance of fertility restoration of three source of cytoplasmic male sterility in rice. Journal of Genetics and Plant Breeding, 49: 93-96

Sreedhar, S., Dayakar, R.T. and Ramesha M.S. 2011. Genetics of fertility restoration of "Wild Abortive" cytoplasmic male sterility in rice (Oryza sativa L.). Current biotica, 4(4):412-418

Suresh, P.B., Srikanth B., Kishore, V.H., Rao, I.S., Vemireddy, L.R., Dharika, N., Sundaram, R.M., Ramesha, M.S., Rao, K.R.S.S., Viraktamath, B.C. and Neeraja C.N. 2012. Fine mapping of Rf3 and Rf4 fertility restorer loci of WA-CMS of rice (Oryza sativa L.) and validation of the developed marker system for identification of restorer lines. Euphytica, 187:421-435

Virmani, S.S. and Edwards, L.B. 1983. Current status and future prospects for breeding hybrid rice and wheat. Adv. Agron. 36: 145-214 
Table 1.Pollen fertility (\%) and spikelet fertility (\%) of F1 plants of an A/R crosscombination for ID type CMS system using ten different restorer lines

\begin{tabular}{l|c|c|l}
\hline Cross combination & $\begin{array}{c}\text { Pollen fertility } \\
(\boldsymbol{\%})\end{array}$ & $\begin{array}{c}\text { Spikelet fertility } \\
(\boldsymbol{\%})\end{array}$ & Fertility status \\
\hline II32A/BR827R & $79 \pm 0.58$ & $80 \pm 2.08$ & Fertile \\
II32A/BR168R & $80 \pm 2.02$ & $82 \pm 0.58$ & Fertile \\
II32A/BR 6723-1- & $79 \pm 0.98$ & $77 \pm 1.53$ & Fertile \\
1-2R & $74 \pm 0.40$ & $77 \pm 2.52$ & Fertile \\
II32A/M.H.63R & $70 \pm 0.81$ & $74 \pm 2.31$ & Fertile \\
II32A/M.H.77R & $78 \pm 1.85$ & $73 \pm 1.00$ & Fertile \\
II32A/Gui 99R & $77 \pm 0.75$ & $75 \pm 1.15$ & Fertile \\
II32A/IR40750R & $72 \pm 1.10$ & $72 \pm 2.52$ & Fertile \\
II32A/IR64R & $73 \pm 0.87$ & $81 \pm 2.08$ & Fertile \\
II32A/Ajaya R & $77 \pm 1.33$ & $71 \pm 1.15$ & Fertile \\
II32A/IR 44675R & & & \\
\hline Restorer line & $77 \pm 4.04$ & $82 \pm 1.53$ & Fertile \\
\hline BR827R & $95 \pm 2.89$ & $88 \pm 1.15$ & Fertile \\
BR168R & $78 \pm 1.15$ & $76 \pm 1.53$ & Fertile \\
BR6723-1-1-2R & $69 \pm 1.73$ & $79 \pm 0.58$ & Fertile \\
M.H.63R & $73 \pm 0.58$ & $76 \pm 2.08$ & Fertile \\
M.H.77R & $79 \pm 2.31$ & $76 \pm 0.58$ & Fertile \\
Gui99R & $77 \pm 0.46$ & $79 \pm 1.53$ & Fertile \\
IR40750R & $75 \pm 1.73$ & $74 \pm 2.52$ & Fertile \\
IR64R & $78 \pm 0.52$ & $81 \pm 2.08$ & Fertile \\
AjayaR & $72 \pm 2.02$ & $72 \pm 2.65$ & Fertile \\
IR44675R & &
\end{tabular}


Table 2. Segregation for pollen fertility restoration in F2 populations involving ID type source of CMS line II32A

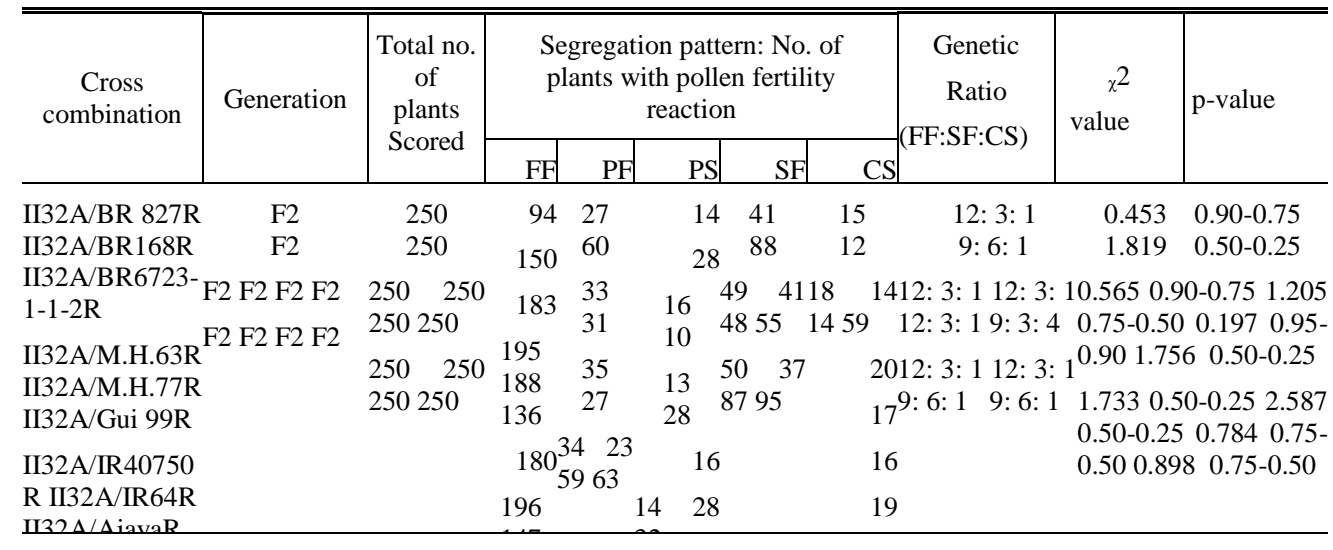

$\mathrm{FF}=$ Full fertile, $\mathrm{PF}=$ Partial fertile, $\mathrm{PS}=$ Partial sterile $, \mathrm{PF}+\mathrm{PS}=\mathrm{SF}($ Semi fertile $), \mathrm{CS}=$ Complete sterile

Table 3. Segregation for pollen fertility restoration in BC1 populations involving ID type sources of CMS line II32A

\begin{tabular}{|c|c|c|c|c|c|c|c|c|c|c|}
\hline \multirow[t]{2}{*}{ Cross combination } & \multirow[t]{2}{*}{ Generation } & \multirow{2}{*}{$\begin{array}{l}\text { Total } \\
\text { no. of } \\
\text { plants } \\
\text { scored }\end{array}$} & \multicolumn{5}{|c|}{$\begin{array}{l}\text { Segregation pattern: No. of } \\
\text { plants } \\
\text { with pollen fertility reaction }\end{array}$} & \multirow{2}{*}{\begin{tabular}{|c} 
Genetic \\
Ratio \\
(FF:SF:C \\
S)
\end{tabular}} & \multirow{2}{*}{$\begin{array}{c}x^{2} \\
\text { value }\end{array}$} & \multirow[t]{2}{*}{ p-value } \\
\hline & & & FF & $\mathrm{PF}$ & PS & SF & $\mathrm{CS}$ & & & \\
\hline II32A//II32A/BR827R & $\mathrm{BC} 1$ & 80 & 35 & 9 & 16 & 25 & 20 & 2: $1: 1$ & 1.88 & $0.50-0.25$ \\
\hline II $32 \mathrm{~A} / / \mathrm{II} 32 \mathrm{~A} / \mathrm{BR} 168 \mathrm{R}$ & $\mathrm{BC} 1$ & 80 & 23 & 7 & 30 & 37 & 20 & $1: 2: 1$ & 0.68 & $0.75-0.50$ \\
\hline \multicolumn{11}{|l|}{ II32A//II32A/BR6723- } \\
\hline $1-1-2 R$ & $\mathrm{BC} 1$ & 75 & 33 & 8 & 14 & 22 & 20 & $2: 1: 1$ & 1.19 & $0.75-0.50$ \\
\hline II32A//II32A/M.H.63R & $\mathrm{BC} 1$ & 90 & 48 & 6 & 13 & 19 & 23 & 2: $1: 1$ & 0.76 & $0.75-0.50$ \\
\hline II32A//II32A/M.H.77R & $\mathrm{BC} 1$ & 85 & 40 & 7 & 15 & 22 & 23 & 2: $1: 1$ & 0.32 & $0.90-0.75$ \\
\hline II32A//II 32A/Gui 99R & $\mathrm{BC} 1$ & 88 & 25 & 11 & 14 & 25 & 38 & $1: 1: 2$ & 1.64 & $0.50-0.25$ \\
\hline II32A//II32A/IR40750R & $\mathrm{BC} 1$ & 100 & 47 & 8 & 19 & 27 & 26 & 2: $1: 1$ & 0.38 & $0.90-0.75$ \\
\hline II32A//II32A/IR 64R & $\mathrm{BC} 1$ & 95 & 47 & 12 & 15 & 27 & 21 & 2: $1: 1$ & 0.77 & $0.75-0.50$ \\
\hline II32A//II32A/AjayaR & $\mathrm{BC} 1$ & 120 & 27 & 21 & 44 & 65 & 28 & $1: 2: 1$ & 0.85 & $0.75-0.50$ \\
\hline II32A//II32A/IR44675R & $\mathrm{BC} 1$ & 105 & 30 & 14 & 31 & 45 & 30 & $1: 2: 1$ & 2.14 & $0.50-0.25$ \\
\hline
\end{tabular}

$\mathrm{FF}=$ Full fertile, $\mathrm{PF}=$ Partial fertile, $\mathrm{PS}=$ Partial sterile, $\mathrm{PF}+\mathrm{PS}=\mathrm{SF}$ (Semi fertile), CS = Complete sterile 


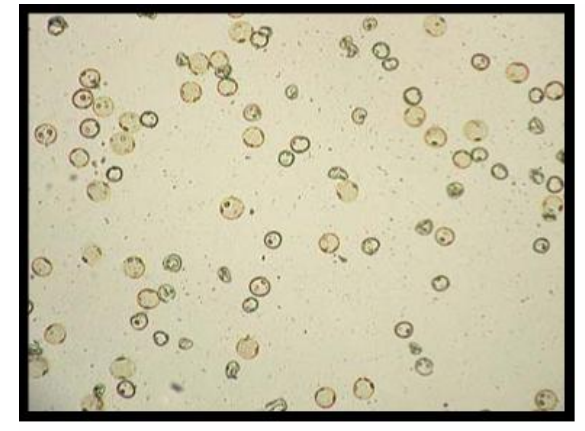

Pic: Completely sterile pollen (CS)

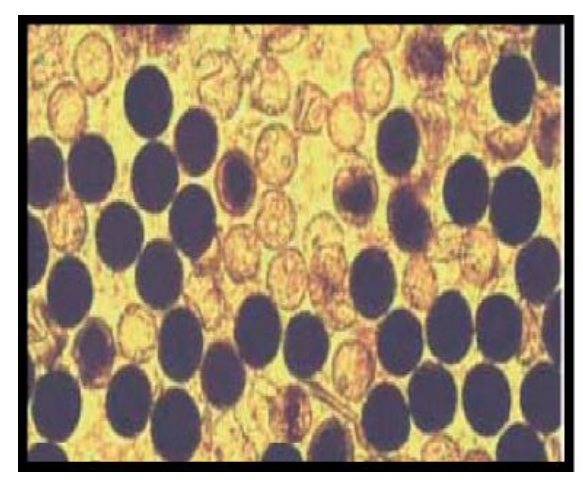

Pic: Partially fertile pollen (PF)

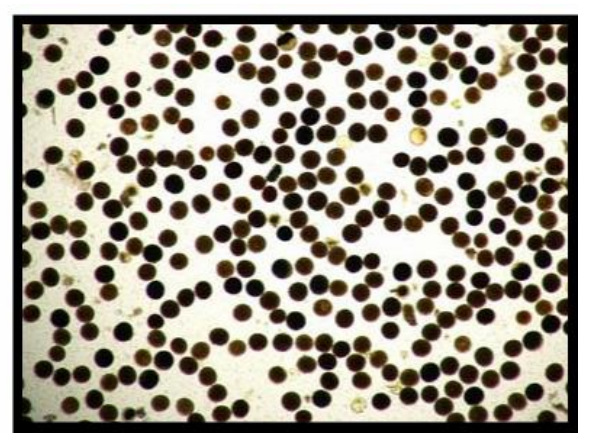

Pic: Full fertile pollen (FF)

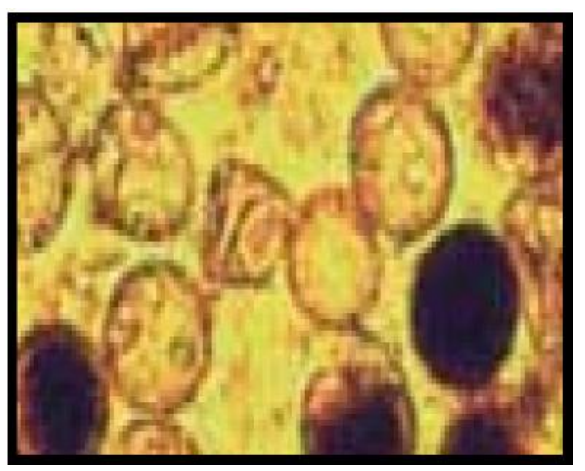

Pic: Partially sterile pollen (PS)

Plate 1. Pollen image categorized as completely sterile, full fertile, partially fertile and partially sterile 